\title{
Clinical characteristics and outcomes in microscopic polyangiitis patients with renal involvement: a study of 124 Chinese patients
}

\author{
Jia Shi ${ }^{1 \dagger}$, Qing Shen ${ }^{1+}$, Xue-Mei Chen ${ }^{2}$ and Xiao-Gang Du ${ }^{1 *}$ (D)
}

\begin{abstract}
Background: Microscopic polyangiitis (MPA) is a systemic autoimmune disease, and renal involvement is frequently present in MPA. MPA patients with renal involvement may have a worse prognosis. In this study, we aimed to evaluate the prognostic factors associated with all-cause death and renal survival in MPA patients with renal involvement.

Methods: A retrospective observational cohort study was performed. One hundred twenty-four patients newly diagnosed with MPA with renal involvement excluding end-stage renal disease (ESRD) who were hospitalized at the First Affiliated Hospital of Chongqing Medical University from January 2012 to July 2017 were included. All the survivors were followed up with until July 2018. The clinical and laboratory data at the time of the initial MPA diagnosis were collected, and the predictive values of the variables for mortality and renal outcome were analysed.

Results: Among the 124 patients, 52 were men (41.9\%) and 72 were women (58.1\%), and the age range was from 25 to 85 years (63.9 \pm 10.6 years). Seventy-six patients $(61.3 \%)$ had pulmonary involvement. Multivariate Cox analysis revealed that age $\geq 65$ years (HR: 2.437; $P=0.021)$, serum creatinine $\geq 500 \mu \mathrm{mol} / \mathrm{L}(\mathrm{HR}=2.207 ; P=0.009)$ and interstitial lung disease (ILD) (HR=2.366; $P=0.013)$ were associated with mortality. Cox multivariate analysis identified that serum creatinine $\geq 500 \mu \mathrm{mol} / \mathrm{L}(H \mathrm{R}=8.236 ; P<0.001)$ and ILD (HR=2.649; $P=0.001)$ were independent detrimental factors for renal survival, and immunosuppressive treatment was a protective factor for renal survival $(H R=0.349 ; P=$ 0.001). The area under the ROC curve (AUC) of the serum creatinine level at diagnosis was 0.705 for mortality and 0.870 for progression to ESRD or the doubling of serum creatinine.

Conclusions: Age, serum creatinine level at diagnosis and ILD were independent predictors of mortality in MPA patients with renal involvement. Serum creatinine level at diagnosis, ILD and immunosuppressive treatment were independently related to renal survival.
\end{abstract}

Keywords: Microscopic polyangiitis, Renal involvement, Clinical characteristics, outcome

\footnotetext{
* Correspondence: cqmudxg@163.com

${ }^{+}$Jia Shi and Qing Shen contributed equally to this work.

'Department of Nephrology, The First Affiliated Hospital of Chongqing

Medical University, Youyi Road 1, Chongqing 400042, China

Full list of author information is available at the end of the article
}

(c) The Author(s). 2019 Open Access This article is distributed under the terms of the Creative Commons Attribution 4.0 International License (http://creativecommons.org/licenses/by/4.0/), which permits unrestricted use, distribution, and reproduction in any medium, provided you give appropriate credit to the original author(s) and the source, provide a link to the Creative Commons license, and indicate if changes were made. The Creative Commons Public Domain Dedication waiver (http://creativecommons.org/publicdomain/zero/1.0/) applies to the data made available in this article, unless otherwise stated. 


\section{Background}

Antineutrophil cytoplasmic antibody (ANCA)-associated vasculitis (AAV) is a systemic autoimmune disease characterized by necrotizing small-vessel inflammation, and it is associated with the presence of myeloperoxidase (MPO)ANCA or proteinase 3 (PR3)-ANCA. AAV compromises microscopic polyangiitis (MPA), granulomatosis with polyangiitis (GPA) and eosinophilic granulomatosis with polyangiitis (EGPA).

The epidemiology and clinical phenotype of AAV patients are different among geographical regions. MPA is the predominant subtype in China and Japan, whereas GPA is more frequent in Northern Europe [1, 2]. The epidemiological manifestations of AAV can be different even among European populations. Higher incidences of MPA were reported in more southern countries, and lower incidences were reported in more northern countries $[1,3]$. The annual incidence of MPA was reported as 2.7 per million in Norway and 11.6 per million in Spain [4]. Regarding the phenotype, MPO is the major target antigen of ANCA in Chinese patients, constituting approximately $80 \%$ of AAV patients [5, 6], whereas twothirds of AAV patients in the United Kingdom were PR3-ANCA-positive [1]. Therefore, the clinical characteristics and outcomes of MPA patients may be different according to different geographic locations. Regarding the ANCA phenotype, a study showed that $67 \%$ of MPA patients were MPO-ANCA positive in the United Kingdom [7] and a higher ratio of MPO-ANCA positivity was reported in Spain (90.4\%) and Japan (varying from 97.1\% to $97.4 \%$ ) [8-10].

Because GPA and PR3-ANCA positivity is more common in European countries, few European studies have focused mainly on the outcome of MPA or MPOANCA-positive patients. MPA is a multiple-system disease, involving primarily the kidneys and lungs, and it is characterized by necrotizing glomerulonephritis and pulmonary capillaritis [11]. Many clinical indexes have been reported to have prognostic value in AAV patients, such as age $[6,12,13]$, haemoglobin level [8], albumin level [14], Birmingham Vasculitis Activity Score (BVAS) [15, 16] and comorbidities [17]. Many studies have shown that AAV patients with worse renal function have a poorer prognosis $[11,13,15,18]$, including patients with MPA $[14,19]$. Given that almost all MPA patients develop renal involvement during the disease course $[4,20]$, the relationship between renal function and prognosis deserves to be studied. Among patients with AAV, interstitial lung disease (ILD) is more common in Japan $(29-39 \%)[8,21]$ than in European countries [22, 23], and AAV patients with ILD has a worse prognosis. However, few data are available regarding the predictors of MPA patients with renal involvement in the Asian region, including China. Since the introduction of immunosuppressive treatment, the prognosis of MPA patients has significantly improved [24-26]. However, immunosuppressive treatments have many severe side effects, including secondary infection, leukopenia, and secondary infection was shown as the leading cause of death during the first year after diagnosis [6]. Consequently, the risk factors of prognosis should be considered when designing therapeutic regimens, especially when designing active immunosuppressive treatment. Our working hypothesis was that age, hemoglobulin level, albumin level, BVAS, renal function, ILD and immunosuppressive treatment can provide prognostic information for Chinese MPA patients with renal involvement.

In the present study, we retrospectively analysed the clinical characteristics and outcome of 124 MPA patients with renal involvement to identify risk factors for renal prognosis and survival.

\section{Methods \\ Cases}

We conducted a retrospective study of patients newly diagnosed with MPA with renal involvement at the First Affiliated Hospital of Chongqing Medical University from January 2012 to July 2017. All patients met the criteria for the diagnosis of MPA according to Watt's algorithm [27]. The exclusion criteria were as follows: age younger than 18 years, secondary vasculitis, other primary or secondary glomerular disease (e.g., lupus nephritis, hepatitis $B$ virus or hepatitis $C$ virus infection) and malignancy. Additionally, end-stage renal disease (ESRD) patients at the time of the initial MPA diagnosis were excluded.

\section{Definition}

Renal involvement was defined by one or more of the following criteria: 1) the presence of pauci-immune necrotizing glomerulonephritis in a renal biopsy; 2) the presence of proteinuria $\geq 300 \mathrm{mg} /$ day and haematuria $(>5$ erythrocytes/high-power field) and/or red blood cell casts, with or without an elevated creatinine level attributed to the disease. The composite of ESRD and doubling of serum creatinine was used as an endpoint of renal death. ESRD was defined as the persistent (more than 3 months) need for renal replacement therapy or permanent reduction in the estimated glomerular filtration rate (eGFR) to $<15 \mathrm{ml} / \mathrm{min}$. The doubling of creatinine was defined as the doubling of serum creatinine for more than 3 months. All-cause mortality was defined as death due to any and all causes. Renal survival was defined as independent renal replacement therapy. Comorbidity was assessed by conditions that had been present before the AAV, namely, a history of coronary heart disease, congestive heart failure, peripheral vascular disease, cerebrovascular disease, chronic pulmonary disease, peptic ulcer disease, liver disease or diabetes. Interstitial lung disease (ILD) was defined by the 
following inclusion criteria: 1) Radiological evidence of ILD on HRCT (such as reticular abnormality or honeycombing with or without traction bronchiectasis), and/ or lung function testing consistent with ILD. 2) The exclusion of another possible aetiological factor (such as drugs and dust) in the development of ILD [28].

\section{Treatment}

The immunosuppressive therapeutic regimen was based on corticosteroids and cytotoxic drugs. For induction therapy, oral prednisone was given at a daily starting dosage of $1 \mathrm{mg} / \mathrm{kg}$ for 4-6 weeks, with reducing doses over time to $12.5-15 \mathrm{mg}$ by 3 months. Patients with lifethreatening or organ-threatening manifestations such as rapidly progressive glomerulonephritis or diffuse alveolar haemorrhage, were given three pulses of intravenous methylprednisolone $(7-15 \mathrm{mg} / \mathrm{kg} /$ day), followed by daily oral prednisone. Cyclophosphamide (CYC) was given as intravenous pulses $(15 \mathrm{mg} / \mathrm{kg})$ every 4 weeks, or it was given orally at a dose of $2 \mathrm{mg} / \mathrm{kg} /$ day. For maintenance therapy, daily oral glucocorticoids and/or methotrexate (MTX) (7.5-12.5 mg every week) was given. No patient received rituximab treatment. Thirty-one patients (25.0\%) did not receive immunosuppressive treatment, and 5 patients received immunosuppressive treatment 412 months after the diagnosis for personal reasons. All survivors were followed up with until July 2018. The average follow-up period was 17 months.

\section{Data collection}

Each patient's clinical data were collected at the time of diagnosis, such as the age, gender, clinical symptoms and signs at first presentation. The laboratory data were as follows: blood haemoglobin level, serum albumin and creatinine ( $\mathrm{Scr}$ ) level, ANCA-antigen specificity (PR3ANCA or MPO-ANCA), C-reactive protein (CRP), erythrocyte sedimentation rate (ESR), 24-hour proteinuria and urinalysis. Imaging data, including chest radiograph, computed tomography and magnetic resonance imaging, were collected. Radiological findings were analysed by two observers blinded to the clinical data, with an inter-observer concordance of $95 \%$. The disease activity at diagnosis and organ involvement were assessed according to the BVAS version 3 [29].

\section{Statistical analysis}

Numeric data were presented as the means and standard deviation or medians (interquartile range) and were analysed using Student's t-test or the Mann-Whitney U test depending on the data distribution. Categorical variables were displayed as frequencies and percentages and were analysed using Chi-squared test and Fisher's exact test. The Kaplan-Meier method was used to estimate survival, and the log-rank test was used to evaluate differences between groups. Univariate and multivariate Cox proportional hazards regression analyses were performed for prognosis and renal survival. Receiver-operating characteristic curve (ROC) analysis was conducted to determine the variables' predictive value for prognosis and renal survival. According to the mean values of our patients, we chose 65 years and $30 \mathrm{~g} / \mathrm{L}$ as cut-off values for the age and serum albumin level, which were also used as cut-off values in previous studies [9, 14, 20, 30]. In China, blood haemoglobin $<90 \mathrm{~g} / \mathrm{L}$ is usually defined as moderate-severe anaemia [31], and the mean blood haemoglobin level of our patients was $88.6 \mathrm{~g} / \mathrm{L}$; thus, we used $90 \mathrm{~g} / \mathrm{L}$ as the cut-off point of blood haemoglobin. Hilhorst et al used $500 \mu \mathrm{mol} / \mathrm{L}$ as the cut-off serum

Table 1 Patients characteristics at diagnosis

\begin{tabular}{ll}
\hline & MPA (N=124) \\
\hline Age (years) & $63.9 \pm 10.6$ \\
Gender (male/female) & $52 / 72$ \\
MPO-ANCA/PR3-ANCA & $117 / 7$ \\
BVAS & $15.9 \pm 5.7$ \\
General manifestation (Myalgia, Arthritis, & $68(54.8 \%)$ \\
Fever $\geq 38^{\circ} \mathrm{C}$, Weight loss $\left.\geq 2 \mathrm{~kg}\right), \mathrm{n}(\%)$ & \\
Cutaneous involvement, $\mathrm{n}(\%)$ & $8(6.5 \%)$ \\
Involvement of mucous membranes/eyes, $\mathrm{n}(\%)$ & $2(1.6 \%)$ \\
Involvement of ear, nose, and throat (ENT), $\mathrm{n}(\%)$ & $1(0.8 \%)$ \\
Pulmonary involvement, $\mathrm{n}(\%)$ & $76(61.3 \%)$ \\
$\quad$ Interstitial lung disease, $\mathrm{n}(\%)$ & $59(47.6 \%)$ \\
$\quad$ Alveolar hemorrhage, $\mathrm{n}(\%)$ & $20(16.1 \%)$ \\
Cardiovascular involvement, $\mathrm{n}(\%)$ & $15(12.1 \%)$ \\
Abdominal involvement, $\mathrm{n}(\%)$ & $3(2.4 \%)$ \\
Nervous system involvement, $\mathrm{n}(\%)$ & $21(16.9 \%)$ \\
Immunosuppressive treatment, $\mathrm{n}(\%)$ & $93(75.0 \%)$ \\
Serum creatinine ( $\mu$ mol/L) & $353.0(133.8-582.5)$ \\
24h urinary protein (mg/24h) & $1608.0(834.8-2552.2)$ \\
Blood hemoglobin (g/L) & $88.6 \pm 19.6$ \\
Serum albumin (g/L) & $30.1 \pm 6.3$ \\
Erythrocyte sedimentation rate (mm/h) & $80.1 \pm 34.1$ \\
Serum C-reactive protein (mg/L) & $71.5(21.7-98.9)$ \\
Coronary heart disease & $12(9.7 \%)$ \\
Heart failure & $7(5.6 \%)$ \\
Cerebrovascular disease & 0 \\
Chronic obstructive pulmonary disease & $6(7.3 \%)$ \\
Peripheral vascular disease & $13(10.5 \%)$ \\
Liver disease & \\
Peptic ulcer disease & 0 \\
\hline
\end{tabular}


creatinine value in prognosis analysis of patients with ANCA-associated glomerulonephritis who presented with a serum creatinine $\geq 500 \mu \mathrm{mol} / \mathrm{L}$ [18], and we also chose $500 \mu \mathrm{mol} / \mathrm{L}$ as cut-off point for serum creatinine A P-value of 0.05 or less was considered significant. All the data above were analysed using SPSS 22.0 statistical software (SPSS Inc, Chicago, IL, USA). Power calculation was conducted using the R package 'powerSurvEpi' [32, 33].

\section{Results}

\section{Characteristics of MPA Patients with renal involvement}

In total, 124 newly diagnosed MPA patients with renal involvement were enrolled in the study. The characteristics of all patients at diagnosis are described in Table 1. There were 52 men $(41.9 \%)$ and 72 women (58.1\%), ranging in age from 25 and 85 years. Because most of our patients refused to have a kidney biopsy for personal reasons, only 25 patients received a kidney biopsy, and we did not analyse the pathological characteristics of renal lesions.
Risk factors for all-cause mortality in MPA Patients with renal involvement

The overall mortality was $37.1 \%$ (46/124) during followup. The 6-month overall mortality was $16.1 \%(20 / 124)$, and the 1-year mortality was $21.8 \%(27 / 124)$. The mortality rates were $32.3 \%(30 / 93)$ and $51.6 \%(16 / 31)$ in patients treated with and without immunosuppressive agents, respectively. Furthermore, the 1-year mortality in patients with ILD was $33.9 \%$ (20/59) while that in patients without ILD was $10.8 \%(7 / 65)$.

The Kaplan-Meier survival curve suggested the following parameters were predictors of a poor prognosis: age $\geq 65$ years $(P=0.001)$, BVAS $\geq 15(P=0.010)$, serum creatinine at diagnosis $\geq 500 \mu \mathrm{mol} / \mathrm{L}(P=0.009)$ and ILD $(P=0.001)$ (Figure 1).

Univariate Cox regression analysis showed that age $\geq 65$ years, serum creatinine $\geq 500 \mu \mathrm{mol} / \mathrm{L}$, haemoglobin $<90 \mathrm{~g} / \mathrm{L}$, BVAS, ILD and abdominal involvement were associated with mortality. Multivariate Cox analysis revealed that age $\geq 65$ years (HR: $2.437 ; P=0.021$ ), ILD (HR: 2.366; $P=$ 0.013 ) and serum creatinine $\geq 500 \mu \mathrm{mol} / \mathrm{L}$ (HR: 2.207; $P=0.009$ ) were independent risk factors (Table 2). The
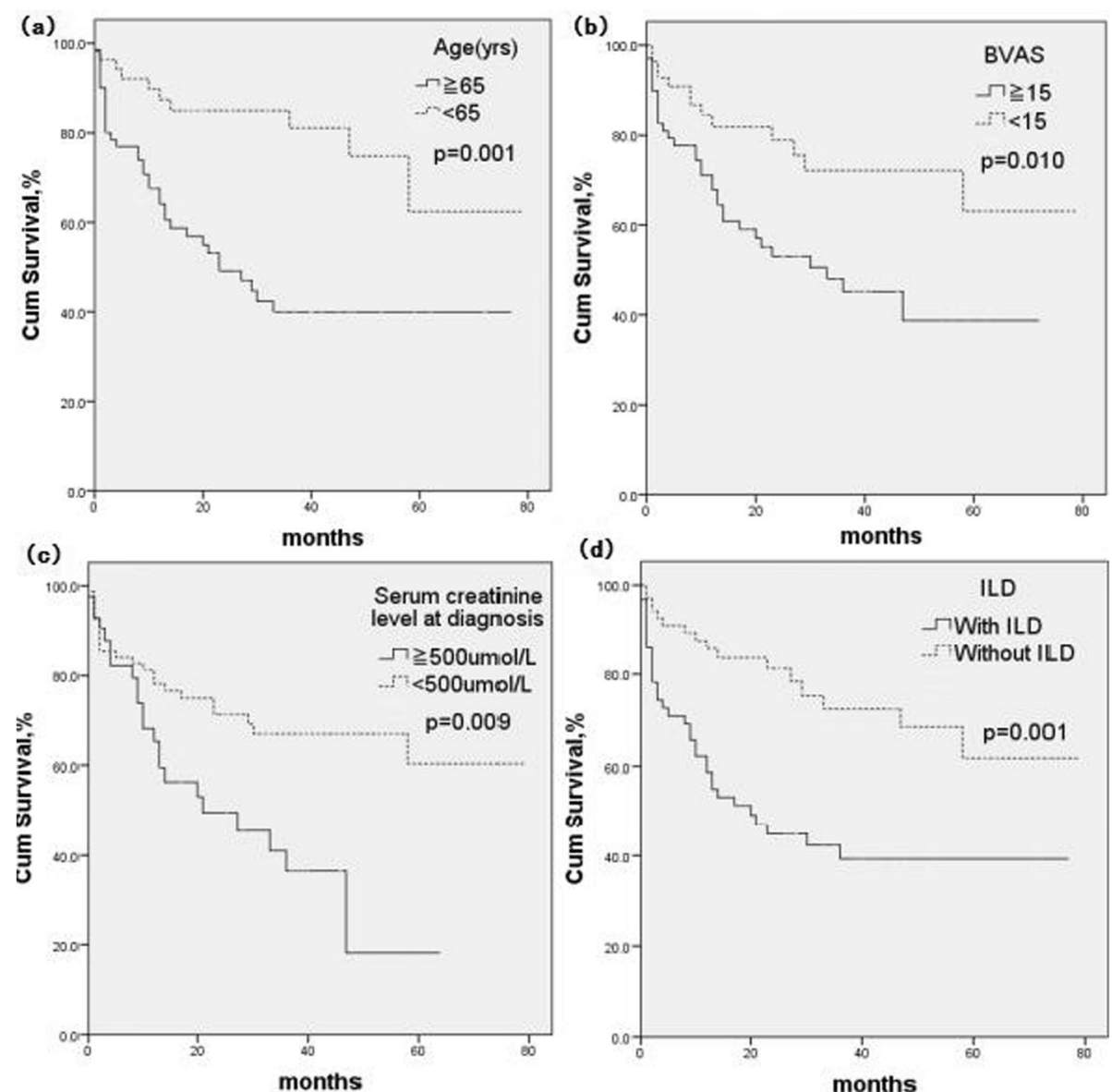

Fig. 1 Risk factors for survival of MPA Patient with renal involvement by the Kaplan-Meier survival curve analysis: age (a), BVAS (b), serum creatinine level at diagnosis (c), ILD (d) 
power calculation showed that the power of age, ILD and serum creatinine for death was 0.79 .

Because the age and serum creatinine at diagnosis were found to be associated with death, we performed $\mathrm{ROC}$ analysis to assess the predictive value of these variables for death. The area under the ROC curve (AUC) of serum creatinine at diagnosis was 0.705 (95\% CI: 0.611-0.799). The optimal cut-off point was $227.0 \mu \mathrm{mol} / \mathrm{L}$ with a sensitivity of $87.0 \%$ and a specificity of $57.7 \%$. The AUC of age was 0.690 (95\% CI: $0.589-0.792)$. The cut-off value of age was 66 years, and the sensitivity and specificity were $71.7 \%$ and $67.7 \%$, respectively (Figure 2 ).

\section{Risk factors for progression to the doubling of serum creatinine or ESRD in MPA Patients with renal involvement}

During the follow-up period, 50 patients $(40.3 \%)$ reached the doubling of serum creatinine or ESRD. Twenty-two (71.0\%) of thirty-one patients who did not receive immunosuppressive treatment progressed to the doubling of serum creatinine or ESRD; however, in 93 patients who received immunosuppressive treatment, only 28 (30.1\%) progressed to the doubling of serum creatinine or ESRD. Kaplan-Meier survival curve analysis suggested that serum creatinine $\geq 500$ $\mu \mathrm{mol} / \mathrm{L}(P<0.001)$ and ILD $(P=0.042)$ were associated with poor renal survival, and patients who received immunosuppressive treatment had a better renal prognosis than those who did not $(P<0.001)$ (Figure 3$)$.

Multiple Cox regression analysis confirmed that serum creatinine $\geq 500 \mu \mathrm{mol} / \mathrm{L}$ at diagnosis (HR: 8.236; $P<0.001$ ) and ILD (HR: 2.649; $P=0.001$ ) were independent predictors of progression to ESRD, and immunosuppressive treatment (HR: $0.349 ; P=0.001$ ) was a protective factor (Table 3). The power calculation showed that the power of serum creatinine, ILD and immunosuppressive treatment for ESRD and the doubling of serum creatinine was 0.88 .

Using ROC, we also confirmed that the serum creatinine level at diagnosis was a predictive factor for renal prognosis. The AUC was 0.870 (95\% CI: 0.806-0.934). The optimal cut-off value of serum creatinine at diagnosis was $325.5 \mu \mathrm{mol} / \mathrm{L}$, and the sensitivity and specificity were $90.0 \%$ and $74.3 \%$, respectively (Figure 4 ).

\section{Discussion}

This study analysed the clinical characteristics and prognostic factors of $124 \mathrm{MPA}$ patients with renal involvement.

Table 2 Univariate and multivariate Cox proportional hazard regression analysis for patient mortality

\begin{tabular}{|c|c|c|c|c|}
\hline & \multicolumn{2}{|l|}{ Univariate } & \multicolumn{2}{|l|}{ Multivariate } \\
\hline & Hazard Ratio(95\%Cl) & $P$ value & Hazard Ratio(95\%Cl) & $P$ value \\
\hline Male gender & $1.594(0.894-2.843)$ & 1.594 & & \\
\hline Age $\geq 65 y$ r (versus $<65 y r$ ) & $3.400(1.684-6.865)$ & 0.001 & $2.437(1.145-5.189)$ & 0.021 \\
\hline Blood hemoglobin $<90 \mathrm{~g} / \mathrm{L}$ (versus $\geq 90 \mathrm{~g} / \mathrm{L}$ ) & $2.977(1.544-5.743)$ & 0.001 & & \\
\hline Serum creatinine $\geq 500 \mu \mathrm{mol} / \mathrm{L}$ (versus $<500 \mu \mathrm{mol} / \mathrm{L}$ ) & $2.172(1.210-3.898)$ & 0.009 & $2.207(1.218-4.000)$ & 0.009 \\
\hline Serum albumin $<30 \mathrm{~g} / \mathrm{L}$ (versus $\geq 30 \mathrm{~g} / \mathrm{L}$ ) & $1.601(0.884-2.899)$ & 0.120 & & \\
\hline General manifestation (Myalgia, Arthritis, Fever $\geq 38^{\circ} \mathrm{C}$, Weight loss $\geq 2 \mathrm{~kg}$ )) & $0.711(0.397-1.273)$ & 0.251 & & \\
\hline Cutaneous involvement & $0.569(0.137-2.362)$ & 0.437 & & \\
\hline Involvement of mucous membranes/eyes & $15.627(3.307-73.844)$ & 0.001 & & \\
\hline Involvement of ear, nose, and throat (ENT) & $0.049(0.001-117546.266)$ & 0.687 & & \\
\hline Interstitial lung disease & $3.296(1.750-6.209)$ & 0.001 & $2.366(1.199-4.667)$ & 0.013 \\
\hline Alveolar hemorrhage & $1.521(0.754-3.066)$ & 0.241 & & \\
\hline Cardiovascular involvement & $1.274(0.569-2.854)$ & 0.556 & & \\
\hline Abdominal involvement & $4.457(1.064-18.662)$ & 0.041 & & \\
\hline Nervous system involvement & $0.708(0.300-1.672)$ & 0.431 & & \\
\hline BVAS & $1.114(1.054-1.177)$ & $<0.001$ & & \\
\hline Immunosuppressive treatment & $0.661(0.360-1.214)$ & 0.182 & & \\
\hline Coronary heart disease & $2.164(1.009-4.643)$ & 0.047 & & \\
\hline Heart failure & $2.935(1.241-6.941)$ & 0.014 & & \\
\hline Chronic obstructive pulmonary disease & $1.466(0.454-4.736)$ & 0.523 & & \\
\hline Liver disease & $4.204(1.006-17.570)$ & 0.049 & & \\
\hline Peptic ulcer & $1.316(0.469-3.691)$ & 0.601 & & \\
\hline Diabetes & $1.522(0.644-3.598)$ & 0.339 & & \\
\hline
\end{tabular}




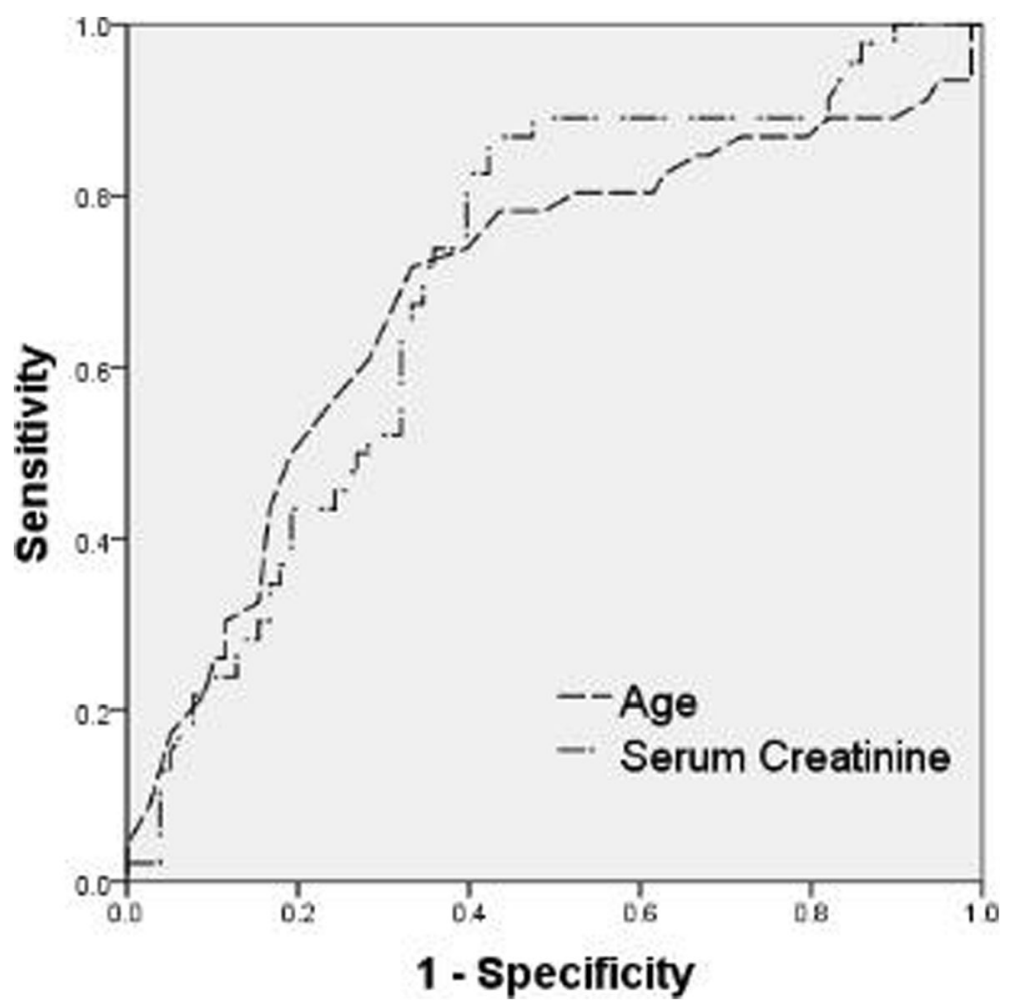

Fig. 2 Receiver-operating characteristic curve (ROC) to determine the diagnostic value of age and serum creatinine level at diagnosis for death

MPA was previously reported to have a slight male predominance in European countries (male: female ratio varied from $1.08: 1$ to $1.4: 1$ ) [7, 34]. However, in our study, the male-to-female ratio was $0.72: 1$, which is similar to what has been reported in Japan (0.75:1) [35]. Whether gender affects the incidence of MPA in China remains uncertain, and much more clinical research is needed. Regarding the ANCA phenotype, a study showed that $67 \%$ of MPA patients were MPO-ANCA positive in the United Kingdom [7], and a higher ratio of MPO-ANCA positivity was reported in Spain (90.4\%) and Japan (varying from 97.1\% to 97.4\%) [8-10]. We also found a similarly high ratio (94.4\%) of MPO-ANCA positivity in MPA patients with renal involvement, which may be attributed to a latitude difference.

In a Japanese study of MPA patients with renal involvement, the survival was $79.5 \%$ at 6 months and $71.1 \%$ at 12 months [19]. Similarly, in our cohort, the overall survival rate at 6 and 12 months were $83.9 \%$ and $78.2 \%$, respectively. Previous studies have shown that age is associated with mortality in AAV patients $[6,12,13]$,
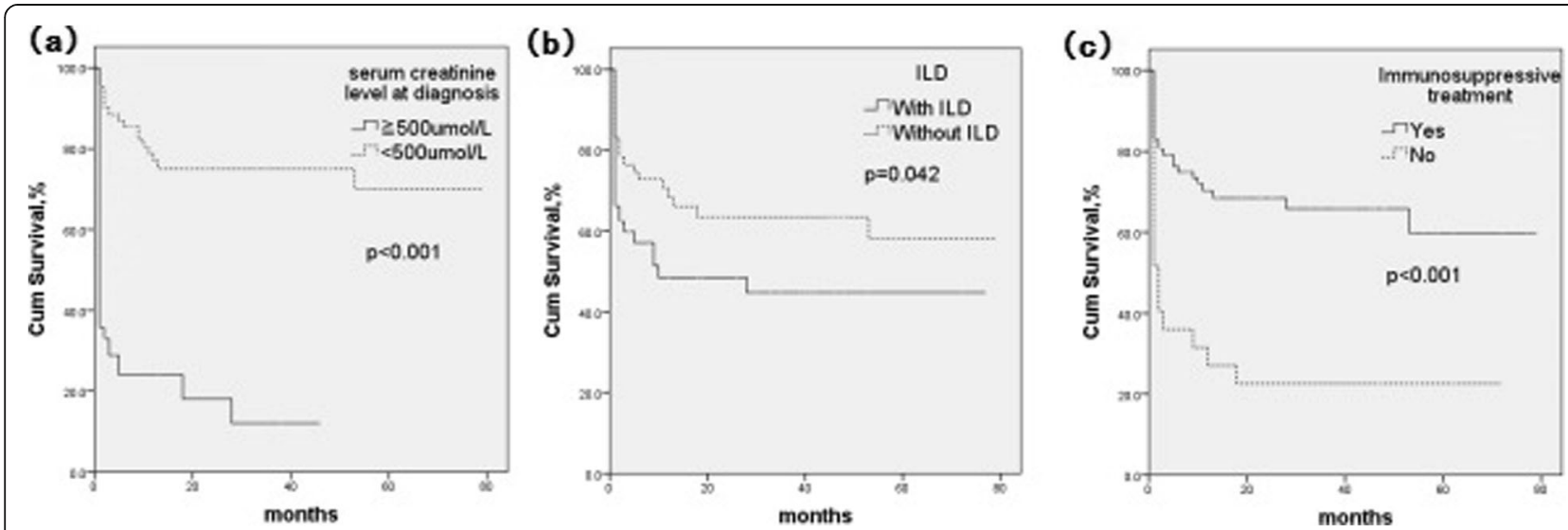

Fig. 3 Risk factors for renal survival of MPA patients with renal involvement by the Kaplan-Meier survival curve analysis: serum creatinine level at diagnosis (a), ILD (b) and immunosuppressive treatment (c) 
Table 3 Univariate and multivariate Cox proportional hazard regression analysis for progression to ESRD

\begin{tabular}{|c|c|c|c|c|}
\hline & Univariate & & Multivariate & \\
\hline & Hazard Ratio $(95 \% \mathrm{Cl})$ & $P$ value & Hazard Ratio $(95 \% \mathrm{Cl})$ & $P$ value \\
\hline Male gender & $1.163(0.665-2.034)$ & 0.596 & & \\
\hline Age65 $\geq y r$ (versus <65yr) & $1.605(0.899-2.867)$ & 0.110 & & \\
\hline Hemoglobin<90g/L (versus $\geq 90 \mathrm{~g} / \mathrm{L}$ ) & $2.749(1.453-5.202)$ & 0.002 & & \\
\hline Creatinine $\geq 500 \mu \mathrm{mol} / \mathrm{L}$ (versus $<500 \mu \mathrm{mol} / \mathrm{L})$ & $8.330(4.515-15.368)$ & $<0.001$ & $8.236(4.340-15.630)$ & $<0.001$ \\
\hline Albumin $<30 \mathrm{~g} / \mathrm{L}$ (versus $\geq 30 \mathrm{~g} / \mathrm{L}$ ) & $0.832(0.477-1.450)$ & 0.832 & & \\
\hline General manifestation (Myalgia, Arthritis, Fever $\geq 38^{\circ} \mathrm{C}$, Weight loss $\geq 2 \mathrm{~kg}$ ) & $0.437(0.247-0.775)$ & 0.005 & & \\
\hline Cutaneous involvement & $0.042(0.000-3.749)$ & 0.167 & & \\
\hline Involvement of mucous membranes/eyes & $2.265(0.309-16.587)$ & 0.421 & & \\
\hline Involvement of ear, nose, and throat (ENT) & $2.826(0.387-20.631)$ & 0.306 & & \\
\hline Interstitial lung disease & $1.793(1.020-3.152)$ & 0.042 & $2.649(1.461-4.802)$ & 0.001 \\
\hline Alveolar hemorrhage & $1.975(1.030-3.785)$ & 0.040 & & \\
\hline Cardiovascular involvement & $1.519(0.713-3.236)$ & 0.279 & & \\
\hline Abdominal involvement & $1.347(0.184-9.866)$ & 0.769 & & \\
\hline Nervous system involvement & $0.470(0.186-1.185)$ & 0.110 & & \\
\hline BVAS & $1.062(1.011-1.114)$ & 0.016 & & \\
\hline Immunosuppressive treatment & $0.296(0.168-0.520)$ & $<0.001$ & $0.349(0.192-0.634)$ & 0.001 \\
\hline Coronary heart disease & $2.318(1.125-4.775)$ & 0.023 & & \\
\hline Heart failure & $2.448(0.871-6.878)$ & 0.089 & & \\
\hline Chronic obstructive pulmonary disease & $0.348(0.048-2.523)$ & 0.296 & & \\
\hline Liver disease & $1.116(0.154-8.095)$ & 0.914 & & \\
\hline Peptic ulcer & $1.491(0.590-3.765)$ & 0.398 & & \\
\hline Diabetes & $1.655(0.776-3.526)$ & 0.192 & & \\
\hline
\end{tabular}

and we also confirmed age $\geq 65$ years was an independent predictor of mortality in MPA patients with renal involvement.

Many studies have reported the association between ILD and MPA [8, 36-38]. AAV patients with ILD have a worse prognosis [36]. In a Japanese cohort study of AAV, 61/156 (39.1\%) patients had ILD [8]. Another Japanese AAV study analysed 1,147 AAV patients and found that the 5-year survival rate of AAV patients with ILD was $50.2 \%$, whereas the 5-year survival rate in those without pulmonary involvement was $73.3 \%$, indicating ILD is a predictor of the 5-year mortality [38]. However, the prevalence of ILD was reported to be only $7.2 \%$ (14/ 194) among MPA patients in London, and no difference in survival was noted between patients with and without ILD [23]. In our study, 59 patients (47.6\%) had ILD. Additionally, 20/59 (33.9\%) of MPA patients with ILD died within the first year, whereas only $10.8 \%$ (7/65) of patients without ILD died. Multiple Cox regression showed that MPA patients with ILD had a 2.4-fold increased risk of death compared with those without ILD, suggesting that ILD is an independent predictor of patient survival. This result was further confirmed in Kaplan-Meier survival curve analysis $(P=0.001)$. We also found that ILD is an independent predictor of renal survival using multiple Cox regression analysis, and the doubling of serum creatinine or the ESRD rate was 2.6 times higher among MPA patients with ILD than among without ILD. To our knowledge, this is the first report of the association between ILD and ESRD, and the mechanism of ILD associated with the progression of renal dysfunction in MPA patients requires further study.

With the introduction of immunosuppressive treatment, the prognosis of MPA patients was significantly improved with the 1-year survival rate ranging from 56\% to $93.9 \%$ [24-26]. We found the overall survival was $62.9 \%$, with a 1 -year survival of $78.2 \%$. The survival rate of patients with immunosuppressive treatment (67.7\%) was higher than it was for those without immunosuppressive treatment $(48.4 \%)$; however, no significant difference was observed between the groups ( $\mathrm{p}=0.053)$, and immunosuppressive treatment was also not found to be significantly associated with overall survival using Kaplan-Meier survival and Cox regression analyses, which was likely due to the sample size not being sufficiently large.

Further study showed that the ratio of patients with a serum creatinine level at diagnosis greater than 178 


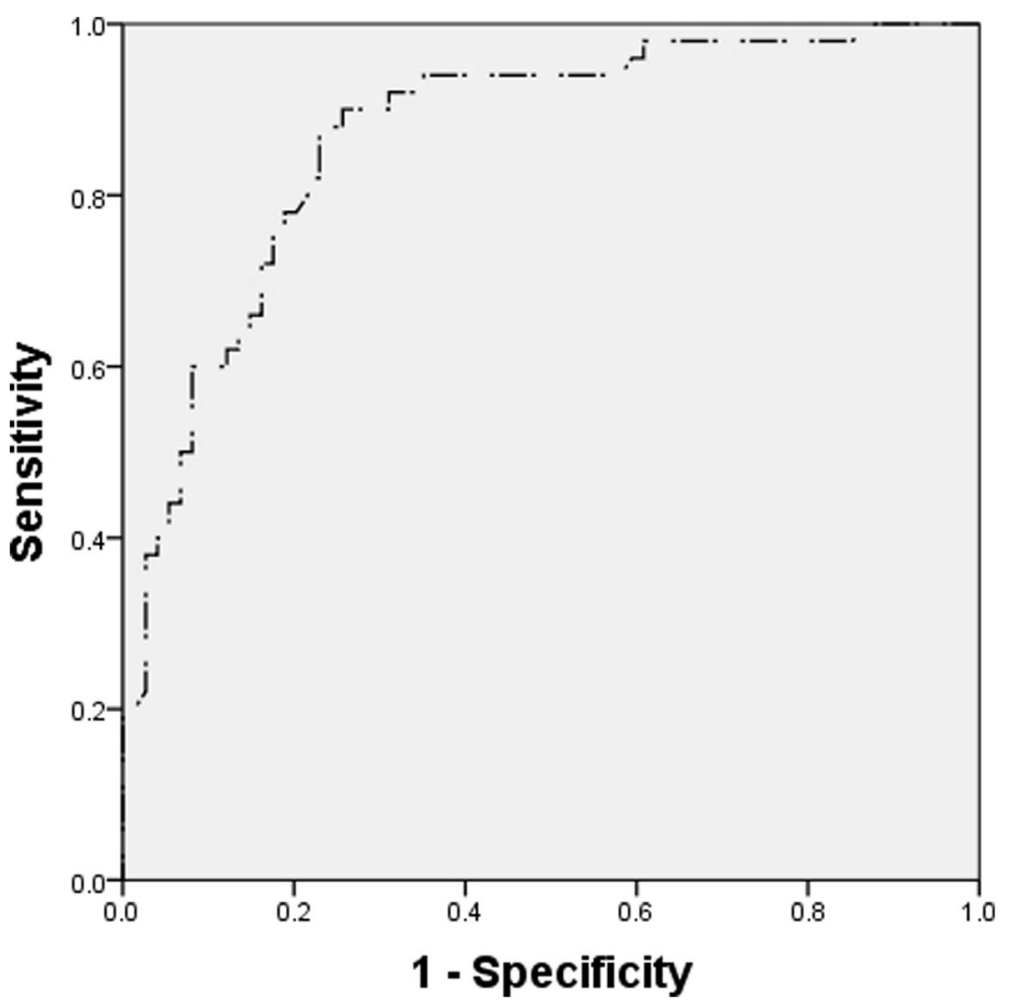

Fig. 4 Receiver-operating characteristic curve (ROC) to estimate the diagnostic value of serum creatinine level at diagnosis for renal prognosis

$\mu \mathrm{mol} / \mathrm{L}$ was $64.5 \%$ (80/124), greater than $443 \mu \mathrm{mol} / \mathrm{L}$ was $37.9 \%$ (47/124), reflecting serious renal injury in patients included in our study. Renal involvement is the major clinical feature of MPA. It was reported that mortality in MPA was significantly higher than in GPA and EGPA, mainly because MPA patients developed severe renal failure at the onset of the disease [6,9]. Wang et al analysed 64 MPA patients with renal involvement showing that the deterioration of renal function is associated with mortality [14], while another report in Japan found that renal function is not associated with overall survival in MPA patients with renal involvement [19]. In this study, a serum creatinine level $\geq 500 \mu \mathrm{mol} / \mathrm{L}$ at diagnosis was an independent predictive factor for both mortality and ESRD, with hazard ratios of 2.207 and 8.236, respectively. A previous study showed that a peak serum creatinine level greater than $4.5 \mathrm{mg} / \mathrm{dl}(397.8 \mu \mathrm{mol} / \mathrm{L})$ at the time of diagnosis is a predictive factor for ESRF or death in AAV patients [39], and another study found that the serum creatinine cut-off level to develop ESRD and require dialysis therapy was $4.6 \mathrm{mg} / \mathrm{dl}$ $(406.64 \mu \mathrm{mol} / \mathrm{L})$ in MPA patients with renal involvement [19]. However, in our study, the ROC showed that the serum creatinine cut-off level at diagnosis for a poor prognosis and renal survival were 227.0 $\mu \mathrm{mol} / \mathrm{L}$ and $325.5 \mu \mathrm{mol} / \mathrm{L}$, respectively.
A previous study found that comorbidities were associated with mortality, and this relationship remained independent of other important clinical characteristics [17]. We also analysed the relationship between comorbidities and the prognosis and renal outcome, while comorbidities were not independent predictors of death or ESRD or the doubling of serum creatinine.

Most deaths among AAV patients occurred within the first month after diagnosis because of the high disease activity and side effects of immunosuppressive treatment, such as serious infections and malignancy [11, 25, 40]. A study of 398 Chinese AAV patients also revealed that secondary infection is the leading cause of death $(53 / 153,39.3 \%)$ during the first year after the diagnosis of AAV [6]. In our study, the peak mortality (43.5\%) was within the first 6 months after diagnosis. However, because most patients passed away outside of the hospital for unknown reasons, we did not perform analysis on cause of death.

We also found that immunosuppressive treatment is an independent protective factor of renal survival, which is in accordance with the result of a previous study [41]. A delayed diagnosis as well as severe lesions in kidneys may lead to a poor treatment response [6, 9]. These findings suggest that an early diagnosis and timely immunosuppressive treatment are important for the renal recovery of MPA patients and may contribute to a good 
prognosis, but immunosuppressive treatment should also be used carefully, especially for patients with severe renal dysfunction [6].

Previous studies have proposed disease activity measured by the BVAS as a predictive factor of patient survival in AAV patients with renal involvement $[15,16]$, while other studies have suggested that BVAS is not statistically correlated with survival in MPA patients with renal involvement $[14,19]$. The BVAS was used to evaluate the symptoms of nine systems. In the study, because all the included patients had renal involvement, most of them developed serious renal injury at diagnosis; thus, the median BVAS was high (15.9). Although patients with a higher BVAS score at presentation had a lower survival rate by Kaplan-Meier survival curve analysis, BVAS was not an independent predictor for the prognosis and renal survival by multivariate Cox proportional hazard regression analysis.

This study has some limitations. First, this was a singlecentre study, with a sample size that was not sufficiently large, which might constitute a sampling error. Second, most patients passed away outside the hospital for undetermined reasons. Consequently, the cause of death could not be analysed, and other factors (outside of those renal related) that predispose to patient death may not be accounted for. Third, the follow-up period was not long enough because some patients entered the study late, especially those enrolled in 2017, possibly leading to the introduction of bias into prognosis analysis. Multi-centre research that uses large samples and has a longer followup duration should be conducted in the future.

\section{Conclusions}

This study showed that age $\geq 65$ years, ILD and serum creatinine $\geq 500 \mu \mathrm{mol} / \mathrm{L}$ at diagnosis are independent predictors of mortality in MPA patients with renal involvement. A high level of serum creatinine at diagnosis and ILD are independent predictors of progression to ESRD or the doubling of serum creatinine, while immunosuppressive treatment is a protective factor for renal survival.

\section{Abbreviations \\ AAV: ANCA-associated vasculitis; ANCA: Antineutrophil cytoplasmic antibody; BVAS: Birmingham Vasculitis Activity Score; CRP: C-reactive protein; CYC: Cyclophosphamide; eGFR: Estimated glomerular filtration rate; EGPA: Eosinophilic granulomatosis with polyangiitis; ESR: Erythrocyte sedimentation rate; ESRD: End stage renal disease; GPA: Granulomatosis with polyangiitis; ILD: Interstitial lung disease; MPA: Microscopic polyangiitis; MPO: Myeloperoxidase; MTX: Methotrexate; PR3: Proteinase 3; ROC: receiver operating characteristic curve; Scr: Serum creatinine}

\section{Acknowledgements}

None.

\section{Author's contribution}

JS and QS contributed equally to this work, and undertook overall study design, analysis and drafting and completion of the manuscript. XD and XC undertook data collection, oversight of analysis, and revision of the manuscript. All authors agreed to be fully accountable for ensuring the integrity and accuracy of the work. All authors read and approved the final manuscript.

\section{Funding}

This work was supported by a grant from the National Natural Science Foundation of China (No.81370816), grants from the Natural Science Foundation of Chongqing Science and Technology Commission of China (No.cstc2012jjA10136) and the Chongqing Municipal Health Bureau of China (No.2011-1-016) to X. Du. The funding body did not play a role in the design of the study and collection, analysis, and interpretation of data and in writing the manuscript.

\section{Availability of data and materials}

The datasets used and/or analyzed during the current study are available from the corresponding author on reasonable request.

\section{Ethics approval and consent to participate}

This study was conducted in accordance with the principles of the Declaration of Helsinki, and the study protocol was approved by the Ethics Committee of The First Affiliated Hospital of Chongqing Medical University (IRB number: 2017-060). We did not obtain written informed consent from all participants, because this was a retrospective observational study.

\section{Consent for publication}

Not applicable.

\section{Competing interests}

The authors declare that they have no competing interests.

\section{Author details}

${ }^{1}$ Department of Nephrology, The First Affiliated Hospital of Chongqing Medical University, Youyi Road 1, Chongqing 400042, China. ${ }^{2}$ Emergency Department, The First Affiliated Hospital of Chongqing Medical University, Youyi Road 1, Chongqing 400042, China.

Received: 15 February 2019 Accepted: 23 August 2019

Published online: 02 September 2019

References

1. Kobayashi S, Fujimoto S. Epidemiology of vasculitides: differences between Japan, Europe and North America. Clin Exp Nephrol. 2013;17(5):611-4.

2. Li ZY, Ma TT, Chen M, Zhao MH. The Prevalence and Management of AntiNeutrophil Cytoplasmic Antibody-Associated Vasculitis in China. Kidney Dis (Basel). 2016;1(4):216-23.

3. Mohammad AJ, Jacobsson LT, Mahr AD, Sturfelt G, Segelmark M. Prevalence of Wegener's granulomatosis, microscopic polyangiitis, polyarteritis nodosa and Churg-Strauss syndrome within a defined population in southern Sweden. Rheumatology (Oxford). 2007:46(8):1329-37.

4. Chung SA, Seo P. Microscopic polyangiitis. Rheum Dis Clin North Am. 2010; 36(3):545-58.

5. Chen M, Yu F, Zhang Y, Zhao MH. Clinical [corrected] and pathological characteristics of Chinese patients with antineutrophil cytoplasmic autoantibody associated systemic vasculitides: a study of 426 patients from a single centre. Postgrad Med J. 2005;81(961):723-7.

6. Lai QY, Ma TT, Li ZY, Chang DY, Zhao MH, Chen M. Predictors for mortality in patients with antineutrophil cytoplasmic autoantibody-associated vasculitis: a study of 398 Chinese patients. J Rheumatol. 2014;41(9):1849-55.

7. Flossmann O, Berden A, de Groot K, Hagen C, Harper L, Heijl C, et al. Longterm patient survival in ANCA-associated vasculitis. Ann Rheum Dis. 2011; 70(3):488-94.

8. Sada KE, Yamamura M, Harigai M, Fujii T, Dobashi H, Takasaki Y, et al. Classification and characteristics of Japanese patients with antineutrophil cytoplasmic antibody-associated vasculitis in a nationwide, prospective, inception cohort study. Arthritis Res Ther. 2014;16(2):R101.

9. Solans-Laque R, Fraile G, Rodriguez-Carballeira M, Caminal L, Castillo MJ, Martinez-Valle F, et al. Clinical characteristics and outcome of Spanish patients with ANCA-associated vasculitides: Impact of the vasculitis type, ANCA specificity, and treatment on mortality and morbidity. Med. 2017; 96(8):e6083. 
10. Smith RM, Jones RB, Jayne DR. Progress in treatment of ANCA-associated vasculitis. Arthritis Res Ther. 2012;14(2):210.

11. Binda V, Moroni G, Messa P. ANCA-associated vasculitis with renal involvement. J nephrol. 2018;31(2):197-208.

12. Weiner M, Goh SM, Mohammad AJ, Hruskova Z, Tanna A, Bruchfeld A, et al. Outcome and treatment of elderly patients with ANCA-associated vasculitis. Clin J Am Soc Nephrol. 2015;10(7):1128-35.

13. Booth AD, Almond MK, Burns A, Ellis P, Gaskin G, Neild GH, et al. Outcome of ANCA-associated renal vasculitis: a 5-year retrospective study. Am J Kidney Dis. 2003;41(4):776-84.

14. Wang Q, Mou S, Xu W, Qi C, Ni Z. Predicting mortality in microscopic polyangiitis with renal involvement: a survival analysis based on 64 patients. Ren Fail. 2013;35(1):82-7.

15. Pu L, Li GS, Zou YR, Zhang P, Wang L. Clinical Predictors of Outcome in Patients with Anti-neutrophil Cytoplasmic Autoantibody-related Renal Vasculitis: Experiences from a Single-center. Chin Med J. 2017;130(8): 899-905.

16. Crnogorac M, Horvatic I, Toric L, Galesic Ljubanovic D, Tisljar M, Galesic K. Clinical, serological and histological determinants of patient and renal outcome in ANCA-associated vasculitis with renal involvement: an analysis from a referral centre. Int Urol Nephrol. 2017:49(8):1419-31.

17. Haris Á, Polner K, Arányi J, et al. Simple, readily available clinical indices predict early and late mortality among patients with ANCA-associated vasculitis. BMC Nephrol. 2017;18(1):76.

18. Hilhorst $M$, Wilde $B$, van Paassen $P$, Winkens $B$, van Breda Vriesman $P$, Cohen Tervaert JW. Improved outcome in anti-neutrophil cytoplasmic antibody (ANCA)-associated glomerulonephritis: a 30-year follow-up study. Nephrol Dial Transplant. 2013;28(2):373-9.

19. Kawai H, Banno S, Kikuchi S, Nishimura N, Nobata H, Kimura Y, et al. Retrospective analysis of factors predicting end-stage renal failure or death in patients with microscopic polyangiitis with mainly renal involvement. Clin Exp Nephrol. 2014;18(5):795-802.

20. Pagnoux C. Updates in ANCA-associated vasculitis. Eur J Rheumatol. 2016; 3(3):122-33.

21. Uezono S, Sato Y, Hara S, Hisanaga S, Fukudome K, Fujimoto S, et al. Outcome of ANCA-associated primary renal vasculitis in Miyazaki Prefecture. Intern Med. 2007;46:815-22.

22. Hervier B, Pagnoux C, Agard C, Haroche J, Amoura Z, Guillevin L, et al. Pulmonary fibrosis associated with ANCA-positive vasculitides. Retrospective study of 12 cases and review of the literature. Ann Rheum Dis. 2009;68:404-7.

23. Arulkumaran N, Periselneris N, Gaskin G, Strickland N, Ind PW, Pusey CD, et al. Interstitial lung disease and ANCA-associated vasculitis: a retrospective observational cohort study. Rheumatology. 2011;50:2035-43.

24. Ahn JK, Hwang JW, Lee J, Jeon CH, Cha HS, Koh EM. Clinical features and outcome of microscopic polyangiitis under a new consensus algorithm of ANCA-associated vasculitides in Korea. Rheumatol Int. 2012;32(10):2979-86.

25. Bourgarit A, Le Toumelin P, Pagnoux C, Cohen P, Mahr A, Le Guern V, et al. Deaths occurring during the first year after treatment onset for polyarteritis nodosa, microscopic polyangiitis, and Churg-Strauss syndrome: a retrospective analysis of causes and factors predictive of mortality based on 595 patients. Med. 2005;84(5):323-30.

26. Oh JS, Lee CK, Kim YG, Nah SS, Moon HB, Yoo B. Clinical features and outcomes of microscopic polyangiitis in Korea. J Korean Med Sci. 2009;24(2): 269-74

27. Watts R, Lane S, Hanslik T, Hauser T, Hellmich B, Koldingsnes W, et al. Development and validation of a consensus methodology for the classification of the ANCA-associated vasculitides and polyarteritis nodosa for epidemiological studies. Ann Rheum Dis. 2007;66(2):222-7.

28. Mikolasch TA, Garthwaite HS, Porter JC. Update in diagnosis and management of interstitial lung disease. Clin Med. 2017;17(2):146-53.

29. Flossmann $O$, Bacon P, de Groot K, Jayne D, Rasmussen N, Seo P, et al. Development of comprehensive disease assessment in systemic vasculitis. Ann Rheum Dis. 2007:66(3):283-92.

30. Andreiana I, Stancu S, Avram A, Taran L. Mircescu G. ANCA positive crescentic glomerulonephritis outcome in a Central East European cohort: a retrospective study. BMC nephrol. 2015;16:90.

31. Dai G, Xiao J, Gao G, Chong X, Wang F, Liang H, et al. Anemia in combined antiretroviral treatment-naive HIV-infected patients in China: A retrospective study of prevalence, risk factors, and mortality. Biosci Trends. 2017;10(6):445-53.
32. Latouche A, Porcher $\mathrm{R}$, Chevret $\mathrm{S}$. Sample size formula for proportional hazards modelling of competing risks.Stat Med. 2004;15;23(21):3263-74.

33. Schoenfeld DA. Sample-size formula for the proportional-hazards regression model. Biometrics. 1983:39:499-503.

34. Agard C, Mouthon L, Mahr A, Guillevin L. Microscopic polyangiitis and polyarteritis nodosa: how and when do they start? Arthritis Rheum. 2003: 49(5):709-15.

35. Sugiyama K, Sada KE, Kurosawa M, Wada J, Makino H. Current status of the treatment of microscopic polyangiitis and granulomatosis with polyangiitis in Japan. Clin Exp Nephrol. 2013;17(1):51-8.

36. Katsumata Y, Kawaguchi Y, Yamanaka H. Interstitial Lung Disease with ANCA-associated Vasculitis. Clin Med Insights Circ Respir Pulm Med. 2015; 9(Suppl 1):51-6.

37. Flores-Suarez LF, Alba MA, Mateos-Toledo H, Ruiz N. Pulmonary Involvement in Systemic Vasculitis. Curr Rheumatol Rep. 2017:19(9):56

38. Hirayama K, Kobayashi M, Usui J, Arimura Y, Sugiyama H, Nitta K, et al. Pulmonary involvements of anti-neutrophil cytoplasmic autoantibodyassociated renal vasculitis in Japan. Nephrol Dial Transplant. 2015;30 Suppl 1:i83-93.

39. Bomback AS, Appel GB, Radhakrishnan J, et al. ANCA-associated glomerulonephritis in the very elderly. Kidney Int. 2011;79(7):757-64.

40. Haris A, Dolgos S, Polner K. Therapy and prognosis of ANCA-associated vasculitis from the clinical nephrologist's perspective. Int Urol Nephrol. 2017; 49(1):91-102.

41. Hu WX, Liu ZH, Liu CB, Tang Z, Wang QW, Chen HP, et al. Prognosis of microscopic polyangiitis with renal involvement: report of 60 Chinese patients. Chin Med J. 2005;118(24):2089-92.

\section{Publisher's Note}

Springer Nature remains neutral with regard to jurisdictional claims in published maps and institutional affiliations.
Ready to submit your research? Choose BMC and benefit from:

- fast, convenient online submission

- thorough peer review by experienced researchers in your field

- rapid publication on acceptance

- support for research data, including large and complex data types

- gold Open Access which fosters wider collaboration and increased citations

- maximum visibility for your research: over $100 \mathrm{M}$ website views per year

At $\mathrm{BMC}$, research is always in progress.

Learn more biomedcentral.com/submissions 